or July weather the number of small creatures harbouring in such a position as, say, a patch of rank herbage near water is truly astonishing. During the last ten years I have often visited such positions in heavy rain, and I am convinced that great mortality is caused, but I have not been able to satisfy myself whether this is due to drowning, burial in the soil, the impact of falling drops, or to some other cause or combination of causes.

Over an area not subject to violent meteorological fluctuations, the fauna will assume a condition of equilibrium. Any sudden and wide departure from the mean conditions for the particular season of the year will have an immediate and profound effect. I venture to write, therefore, in the hope that someone will pay special attention to the effects of such periods of abnormal rainfall as we have had during the last few months. The subject does not appear to have received the attention it merits, and the inquiry might profitably be extended so as to cover other meteorological effects.

W. Ruskin ButTERFIELD.

4 Stanhope Place, St. Leonards-on-Sea, January 17.

\section{Subjective Images.}

ThE letter on the above subject (p. 27I) reminds me of one that I sent to NATURE in 1871 (vol. iv. p. 122) describing a phenomenon complementary to that observed by $\mathrm{Mgr}$. Molloy. I was induced to write it in consequence of a communication by $\mathrm{Mr}$. T. .Ward (NATURE, vol. iv. p. 68), who observed that the white chalk lines on a blackboard appeared to be blue when the sun was shining on his eyes I noticed that the printing in a book looked bright red when I was walking on a chalk road, the book being shaded by an umbrella.

There appears to be a connection between the three phenomena, but I will not venture to suggest an explanation; possibly the persistence of colours may be different in different eyes.

HERBERT MCLeod.

January 23 .

IN response to Dr. Molloy's appeal, I may mention that a correspondent of Work having asked the reason for the colours in Benham's artificial spectrum top, I made, in the number for April 6, 1895, a suggestion which is practically the same as his explanation. This was that the optic nerves which according to the Young-Helmholtz theory produce the sensation of violet, are the most easily excited of the three sets, and that those producing the sensation of green, having the greatest inertia, are least easily excited and retain the impression for a longer time than the other two. In the number of the same journal for January 11 , $1896 \overline{6}$, other phenomena were cited which might be explained by the same hypothesis.

Alex. Thurbura

$$
\text { Keith. }
$$

Ir seems probable that the effect mentioned by Dr. Gerald Molloy in your issue of January $2 \mathrm{I}$ is the same effect-produced in a different way-as that I spoke of in my letter published in Nature of January 14.

In the instance he mentions we have black letters on a white marble slab, viewed by eyes in a partially dazzled state from the effect of strong sunlight. In the case to which I directed attention, these conditions are almost reproduced viz. the blackened silver bromide on a white porcelain dish under a dazzling red light. Before the developing solution is added, the bromide under the red light appears as a grey powder in a white dish, but on adding the developing solution it is blackened, and when the liquid is poured off the change from black to bright green may be conveniently observed. The angle at which the dish is viewed seems not to be without influence on the brightness of the colour. Under the best conditions the bromide has the appearance of masses of uncut emeralds.

Ley Hill House, Sutton Coldfield, January 2.3.

\section{Abysmal Deposits.}

I BELIEVE there is some difficulty in accounting for the difference in the distribution of living Foraminifera at the surface of the sea and of deposits of their skeletons at the bottom. As is well known, the abysmal deposits contain Nก. 1787 , vOL. 69] no Foraminifera, while the much vaster pelagic deposits consist chiefly of them. The difference in depth has suggested that in the case of the pelagic deposits the free carbonic acid in the water has not had time to dissolve the sinking skeleton, while it has had time before a skeleton can reach the greater depths occupied by the abysmal deposits. But surely if this were the whole truth some effect would have been produced by the time the skeleton had sunk 2000 or 2500 fathoms or even less, so that it ought to be impossible to find, as we do, perfect skeletons in the globigerina ooze.

I wish to suggest a theory which is new, so far as I know, viz. that solution does occur, but does not begin until the organic matter protecting the carbonate of lime has all putrefied away. Hence the solution may be begun and ended in the excess of depth which the abysmal parts of the ocean-bed have over the pelagic parts.

29 Hurlbutt Street, Newington Butts, S.E.

\section{Spelling Reform.}

IN your review of Dr. Joseph Bowden's "Elements of the Theory of Integers," there is included a severe condemnation of the very moderate instalment of spelling reform which the author appears to have introduced into his work. A discussion on the general question of spelling reform would, of course, not be suitable to your pages, and I therefore confine myself to making a respectful remonstrance against your reviewer's sweeping condemnation of what I conjecture to be an attempt to remedy a few of the glaring inconsistencies and anomalies of the current English spelling. Other languages have, from time to time, re formed their spelling so as to bring it more into harmony with the pronunciation, and this has been the case in our own time with German. It can scarcely be doubted that, sooner or later, the same will be the case with English. In that event the spellings you quote will certainly be adopted, with the exception of "fixd," which will, of course, be spelt fixt.

T. B. S.

Edinburgh, January 15 .

MaY I point out that Dr. Bowden's book purports to deal with the "Elements of the Theory of Integers," and not with questions of spelling reform? Neither on the title-page nor in the preface does the author make any claim to address his work to those members of the community who prefer to have their thoughts expressed in a written language differing from that of their fellow beings. Failing any such indication, it must be assumed that the work is intended to be read and criticised by English speaking and English writing readers of the present day, to whorn the author's spelling of the words in question must appear tc be grossly incorrect. I quite agree with $T$ : B. S. that " a discussion of the general question of spelling reform," as exemplified by the modern German equivalent of red, would "not be suitable to your pages."

The REviewer

\section{RESEARCHES RELATING TO RADIUM.}

THE year just passed has witnessed a widespread interest among all classes of people in Mme. Curie's discovery of radium, and attention has been generally directed to the nature of the new property of matter which it exhibits to such a surprising degree. The far-reaching consequences of $M$. Becquerel's discovery of radio-activity for the element uranium on our ideas with regard to the relations between energy and matter, although they have been long recognised by those immediately connected with the development of the subject, are now universally admitted. The million-fold more powerful radium appeals to the practical as well as to the academic imagination, and the problems raised by the new property have been brought into universal prominence. Owing to the excellent work of Giesel in improving the methods of extracting the new element from its 